Article

\title{
Can Video Surveillance Systems Promote the Perception of Safety? Evidence from Surveys on Residents in Beijing, China
}

\author{
Hanqi Zhang ${ }^{1,2}$, Jianfeng Guo ${ }^{1,2}$, Chao Deng ${ }^{1,2}$, Ying Fan ${ }^{3}$ and Fu Gu ${ }^{4,5, *(D)}$ \\ 1 Institutes of Science and Development, Chinese Academy of Sciences, Beijing 100190, China; \\ zhqsunny@163.com (H.Z.); guojf@casipm.ac.cn (J.G.); dengchao1123@139.com (C.D.) \\ 2 School of Public Policy and Management, University of Chinese Academy of Sciences, Beijing 100049, China \\ 3 School of Economics and Management, Beihang University, Beijing 100191, China; yfan1123@buaa.edu.cn \\ 4 Department of Industrial and System Engineering, Zhejiang University, Hangzhou 310027, China \\ 5 National Institute of Innovation Management, Zhejiang University, Hangzhou 310027, China \\ * Correspondence: gufu@zju.edu.cn
}

Received: 28 February 2019; Accepted: 12 March 2019; Published: 15 March 2019

check for updates

\begin{abstract}
Ubiquitous utilization of video surveillance systems is supposed to promote safety, yet whether these systems improve the residents' perception of safety is unknown. Moreover, the factors that affect the perception of safety are also unclear. We seek to fill these knowledge gaps via a survey-based study, which aims at evaluating the impact of video surveillance systems on perceived safety from crimes and accidents and on behavioral preferences, as well as the attitudes towards such systems. A total of 1080 residents in Beijing, China are validly surveyed, and the surveys returned are exploited for univariate analysis and regression analysis. The analysis results indicate that female respondents are more accustomed to adopt video surveillance systems, as they feel safer and more comfortable with the existence of surveillance systems. Higher levels of education, greater length of residency, and richer knowledge of surveillance systems tend to increase the perception of safety, while age and monthly income act negatively. The effects of these factors should be considered during the implementation of video surveillance systems and recommendations are given to facilitate the adoption of such systems.
\end{abstract}

Keywords: video surveillance system; perception of safety; survey; univariate analysis; regression analysis

\section{Introduction}

Presently, video surveillance systems are ubiquitously implemented in both public and private environments, including airports, stations, highways, subways, parking lots, plazas, stores, shopping malls, offices, schools, universities, and homes. The primary driver to implement video surveillance systems is the increasing concern of safety [1-3]. To this end, these systems are endowed with corresponding functionalities, such as object tracking [4,5], face recognition [6-8], personal profiling [9], behavioral analysis $[10,11]$, and accident analysis [1]. Video surveillance systems have become an indispensable part of modern safety management of public and private sectors and the installation of these systems shows no sign of stopping. It is of critical importance to examine whether video surveillance systems affect residents' perceptions of safety, as the answer to this question is vital for understanding the purposefulness and sustainability of such systems. However, only a few scholars discussed this issue and most of them focused on detailed segments, such as the perception of safety in schools $[12,13]$ or on the road $[14,15]$. 
On the other hand, the extensive applications of video surveillance systems arise privacy concerns, particularly in the context of smart cities where surveillance is pervasive [16-19]. Aside from technical measures and legal regulations that secure privacy [20], personal acceptance and support for surveillance is recognized as another important dimension that affects the adoption of any surveillance [21] or infrastructure [22]. In addition, behavioral preferences are also worth investigating during implementation of video surveillance systems, as they can serve as a necessary supplement to the attitudes towards these systems. Yet, to the best of our knowledge, there is little knowledge about the factors and preferences that are related to the adoption of video surveillance systems.

To address the aforementioned knowledge gaps, here we conducted a survey-based study to investigate the impact of video surveillance systems on the perception of safety, as well as the factors that are related to personal acceptance and support of such systems. A questionnaire was developed based on reviewing the literature, with the objective of acquiring the perceived safety that is associated with video surveillance systems, including behavioral preferences and attitudes, from a wide spectrum of residents in Beijing, the capital city of China. Beijing is amongst the first cities to implement a nationwide video surveillance project, namely "Skynet", which was launched in early 2005 [23]. By 2015, the coverage of the monitoring system was 100\% [23]. With a total population of 21.71 million [24] and a sophisticated network of video surveillance systems, Beijing presents an ideal location for this study. Based on the validly returned questionnaires, we conducted univariate analysis to identify the influences of personal characteristics, including gender, age, education, income, occupation, residence, experience, and knowledge, on the perceived safety, which is measured by a series of questions based on Likert scales. Furthermore, we extracted two factors from the answers using principle component analysis and performed a regression analysis to examine the influential personal characteristics on the two factors.

In summary, this work has two major contributions. First, we surveyed the perceived safety of video surveillance systems from a wide range of respondents in a city with sophisticated surveillance infrastructure. For the purpose of facilitating the sustainable development of video surveillance systems, it is highly desirable to obtain the perception of safety of these systems from a broader selection of respondents, but this information is always in short supply. The extant literature primarily evaluates the impacts of surveillance cameras on the perceived safety of students $[12,13]$ or drivers $[14,15]$. Second, we paid specific attention to examining the effects of personal characteristics in the adoption of video surveillance systems. Specifically, attitudes and preferences have been included in the survey, offering a better understanding of the influential factors that affect personal acceptance and support of video surveillance. Based on the results, we provided recommendations on education and location of video surveillance systems, with the objective of promoting the perceived safety and acceptance of such systems.

The remainder of this paper is organized as follows. A review of the related literature is presented in Section 2. Section 3 illustrates the design of questionnaire and the procedure of the analysis. Section 4 presents the results of the survey and analysis. Section 5 discusses the shortcomings of this work and offers recommendations for practitioners. Section 6 concludes this study and gives potential directions of future research.

\section{Related Works}

Only a few researchers have considered the perceived safety of video surveillance systems, some of them concerned about the perceived safety of video surveillance systems in schools. Brown surveyed a selection of 230 high school students, but his results were not conclusive on whether the video surveillance cameras increase safety [12]. Based on a national-scale survey of students from middle and high schools, Johnson et al. found that outside cameras promote the perceived safety, while inside cameras tend to increase psychological stress [13]. The works of Brown [12] and Johnson et al. [13] show that female students' perceptions of the safety of video surveillance cameras were less than those of male students. 
Another cluster of relevant literature examines the perceptions and attitudes towards video surveillance systems in traffic systems. Porter and Berry surveyed 880 licensed drivers in the United States and found that cameras were not generally preferable [14]. On the basis of 261 survey responses, Higgins et al. pointed out that drivers generally want fewer surveillance cameras [15]. However, the official statistics and self-reports confirm that the installation of such equipment has indeed significantly reduced the occurrences of road accidents $[25,26]$ and other misconducts, such as running red lights $[27,28]$. The divergence between behaviors and attitudes can be attributed to the psychological pressure that is imposed by the presence of video surveillance systems.

Aside from imposing stress, video surveillance systems can alter decisions and subsequent behaviors through some psychological effects. For example, van Bommel et al. showed that the presence of video surveillance systems, a webcam in the case, affects helping behaviors [29]. A camera can reverse the so-called "bystander effect", which originally refers to a phenomenon that individuals are less likely to help others when other people are present [30]. Van Bommel et al. found that the reverse of "bystander effect" can be attributed to increased self-awareness, which is likely to be triggered by the presence of the surveillance camera [29]. This observation is associated with the term of situation awareness, which usually makes people more cautious [31]. On the other hand, self-awareness and caution lead to self-regulation [32], probably resulting in less misconducts and misbehaviors, as well as better public security and social well-being. Therefore, the psychological effects, in particular, caution that is stimulated by self-awareness or situation awareness, could also affect the adoption of video surveillance systems.

In sum, the extant literature on the perceptions and attitudes towards video surveillance systems only surveys certain groups, such as students and drivers. With ever-increasing applications of video surveillance systems, a broader range of respondents are highly desirable for examining how these systems affect the perceived safety, preferences, and attitudes of residents. This would provide a more comprehensive view on peoples' perceptions regarding the adoption of video surveillance systems, from which insights and recommendations can be provided to ensure the sustainable development of such systems.

\section{Methods}

\subsection{Questionnaire Design}

Based on the above literature review, we here included a series of demographic features, namely, gender, age, level of education, monthly income (in RMB), occupation, and length of residence in Beijing. The first five personal characteristics are frequently used in survey-based studies on large-scale population, for example, disposal behaviors of waste electric and electronic equipment $[33,34]$, drivers' self-reported red-light running [14], and determinants that affect the adoption of wind power generators [35] or the generation of household food wastes [36]. The last attribute was proposed based on the assumption that the knowledge and acceptance of video surveillance systems would be positively correlated with the duration of time being in a city with sophisticated surveillance systems, in this case, Beijing, the capital city of China.

Furthermore, we employed the following set of three questions to acquire the respondent's knowledge about video surveillance systems: (a) "Whether they contact video surveillance systems in life?", (b) "whether they handle video surveillance system in work?", and (c) "do you have knowledge about the structure and operation of any surveillance systems?". This was due to the fact that knowledge plays an important role in the adoption of technologies, particularly those of high controversy, such as nuclear energy [37], hydrogen storage [38], and human papillomavirus vaccination [39]. In our subsequent regression analysis, we exploited the answers to these questions as control variables.

Taking the insights from previous studies on video surveillance systems [12,13], the literature on public lights [22], and the reviewed psychological studies [29,31,32], we developed nine survey 
questions to obtain the perceived safety and preferences and attitudes towards such systems, including Q10 — crime reduction by video surveillance systems (perceived safety), Q11—accident reduction by video surveillance systems (perceived safety), Q12 - the quantity of video surveillance systems is sufficient (attitudes), Q13 - preference for housings with surveillance systems (preferences), Q14-preference for routes with surveillance systems (preferences), Q15-the presence of video surveillance systems makes people cautious (attitudes), Q16-video surveillance systems impose pressure (attitudes), Q17-active video surveillance systems enhance the above effects (attitudes), Q18-the diminishment or absence of video surveillance systems threat the public security (perceived safety). Moreover, we parameterized the questionnaire, as shown in Table 1. The higher values of the questions of perceived safety and preferences and the lower values of the questions of attitudes indicate the respondents are positive towards adopting video surveillance systems. The complete form of the questionnaire consists of the three sections, namely, demographic information of the respondent, knowledge about video surveillance systems, and perceptions and attitudes towards video surveillance systems, see Table A1. The questions of the third section uses Likert scaling, one of the most widely used psychometric scales in survey-based research $[40,41]$, in particular, the surveys on perceptions and attitudes towards surveillance systems, see $[13,15,21]$.

Table 1. Descriptive variables from the questionnaire.

\begin{tabular}{|c|c|c|c|}
\hline Section & Variable (Notation) & Description (Question) & Values (Options for Selection, Dummies) \\
\hline \multirow{6}{*}{ Demographic } & $\operatorname{sex}$ & Gender & "1" for male, and " 0 " for female \\
\hline & age & Age & $\begin{array}{l}\text { " } 1 \text { " for below } 20 \text {, " } 2 \text { " for } 20 \text { to } 35, \text {, } 3 \text { " for } 35 \text { to } 50 \text {, " } 4 \text { " for } 50 \\
\text { to } 65 \text {, " } 5 \text { " for over } 65\end{array}$ \\
\hline & $e d u$ & Level of education & $\begin{array}{l}\text { " } 1 \text { " if the respondent only finished high school or below, " } 2 \text { " } \\
\text { for technical degree or bachelor degree, and " } 3 \text { " for master } \\
\text { degree or above }\end{array}$ \\
\hline & inc & Monthly income, in RMB & $\begin{array}{l}\text { "1" for below } 3500 \text { RMB, "2" for } 3500 \text { to } 10,000 \text { RMB per } \\
\text { month, " } 3 \text { " for } 10,001 \text { to } 20,000 \text { RMB per month, and " } 4 \text { " for } \\
\text { above } 20,000 \text { RMB }\end{array}$ \\
\hline & job & Occupation & $\begin{array}{l}\text { " } 1 \text { " if the respondent works as a civil servant, " } 2 \text { " if the } \\
\text { respondent works in another public sector, " } 3 \text { " if the } \\
\text { respondent is self-employed, " } 4 \text { " if the respondent works for } \\
\text { a private firm, and " } 5 \text { " otherwise }\end{array}$ \\
\hline & year & Length of residence in Beijing & $\begin{array}{l}\text { " } 1 \text { " if the respondent only lives in Beijing for less than one } \\
\text { year, " } 2 \text { " for one to five years, " } 3 \text { " for five to ten years, and } \\
\text { " } 4 \text { " for over ten years }\end{array}$ \\
\hline \multirow{3}{*}{ Knowledge } & cil & $\begin{array}{l}\text { Whether contact video surveillance } \\
\text { system in life? }\end{array}$ & "1" for the answer of "yes", “0" for "no" \\
\hline & $c i w$ & $\begin{array}{l}\text { Whether handle video surveillance } \\
\text { system in work? }\end{array}$ & “1" for the answer of "yes", “0" for "no" \\
\hline & kno & $\begin{array}{l}\text { Do you have knowledge about the } \\
\text { structure and operation of any } \\
\text { surveillance systems? }\end{array}$ & "1" for the answer of "yes", "0" for "no" \\
\hline \multirow{9}{*}{ Perception } & cri & $\begin{array}{l}\text { Video surveillance systems can reduce } \\
\text { crimes }\end{array}$ & $\begin{array}{l}\text { "1" for strongly disagree (SD), "2" for disagree (D), "3" for } \\
\text { neither disagree nor agree (NN), "4" for agree (A), and " } 5 \text { " } \\
\text { for strongly agree (SA) }\end{array}$ \\
\hline & $a c c$ & $\begin{array}{l}\text { Video surveillance systems can reduce } \\
\text { accidents }\end{array}$ & “1” for $\mathrm{SD}$, “2” for $\mathrm{D}$, , 3 ” for $\mathrm{NN}$, “ 4 ” for $\mathrm{A}$, and “ 5 ” for $\mathrm{SA}$ \\
\hline & eno & $\begin{array}{l}\text { Current quantity surveillance cameras } \\
\text { are enough }\end{array}$ & "1" for $\mathrm{SD}$, " 2 " for $\mathrm{D}$, , 3 " for $\mathrm{NN}$, " 4 " for $\mathrm{A}$, and " 5 " for $\mathrm{SA}$ \\
\hline & saf & $\begin{array}{l}\text { Residence with video surveillance } \\
\text { systems are safer }\end{array}$ & “1" for $\mathrm{SD}$, “2" for $\mathrm{D}$, , 3 ” for $\mathrm{NN}$, " 4 " for $\mathrm{A}$, and " 5 " for $\mathrm{SA}$ \\
\hline & cho & $\begin{array}{l}\text { Choose routes with video surveillance } \\
\text { systems would be more preferable }\end{array}$ & “1" for $\mathrm{SD}$, “2" for $\mathrm{D}$, , 3 ” for $\mathrm{NN}$, “4” for $\mathrm{A}$, and " 5 " for $\mathrm{SA}$ \\
\hline & cau & $\begin{array}{l}\text { The presence of video surveillance } \\
\text { systems makes people behave more } \\
\text { cautious }\end{array}$ & “1” for $\mathrm{SD}$, “" 2 ” for $\mathrm{D}$, “ 3 ” for $\mathrm{NN}$, “ 4 ” for $\mathrm{A}$, and “ 5 ” for $\mathrm{SA}$ \\
\hline & pre & $\begin{array}{l}\text { Video surveillance systems bring } \\
\text { pressure on people }\end{array}$ & “1" for $\mathrm{SD}$, " 2 " for $\mathrm{D}$, , 3 ” for $\mathrm{NN}$, " 4 " for $\mathrm{A}$, and " 5 " for $\mathrm{SA}$ \\
\hline & enh & $\begin{array}{l}\text { Moving surveillance cameras enhance } \\
\text { above perceptions, i.e., caution and } \\
\text { pressure }\end{array}$ & "1" for $\mathrm{SD}$, " 2 " for $\mathrm{D}$, " 3 " for $\mathrm{NN}$, " 4 " for $\mathrm{A}$, and " 5 " for $\mathrm{SA}$ \\
\hline & wor & $\begin{array}{l}\text { Less or no video surveillance systems } \\
\text { would worsen public security }\end{array}$ & "1" for $\mathrm{SD}$, “2" for $\mathrm{D}$, , "3" for $\mathrm{NN}$, “4” for $\mathrm{A}$, and " 5 " for $\mathrm{SA}$ \\
\hline
\end{tabular}

The questionnaires were distributed online and the period was from 24 June 2018 to 31 October 2018. Compared to conventional offline surveying methods, online distribution of questionnaires is thought to be of a broader coverage, with high speed and high efficiency [42]. Besides, the results of online surveys are comparable to those of offline surveys, particularly in surveying personal attitudes 
and preferences $[43,44]$. The questionnaire was published through WJX (www.wjx.cn), a survey app based on WeChat, which is one of the most popular social networking platforms in the world, with over $1000 \mathrm{M}$ monthly active users [45]. The Internet Protocol (IP) addresses of the respondents were recorded, to exclude undesirable responses from the IP addresses outside Beijing and duplicate responses from the same IP addresses. We also acquired the time spent on filling the questionnaire and any questionnaires that were filled within $18 \mathrm{~s}$ were excluded, since this does not conform to the average reading habits of human beings [46].

\subsection{Univariate Analysis}

We examined the impacts of each of the six personal characteristics on the answers to the nine questions using univariate analysis, or so-called one-way analysis of variance (ANOVA), and the statistical significance of the impacts were also acquired.

\subsection{Regression Analysis}

In this work, we employed a regression analysis to identify the effects of personal characteristics in a combined manner. In this regression analysis, we first employed principal component analysis (PCA) to extract common factors, in this case, principal components (PCs), from the answers to the questions of perceptions and attitudes towards video surveillance systems, that is, the nine questions. The calculation procedure of PCA is the same as the previous studies on identifying the influential components in composites [47,48], a classical PCA method [49]. An orthogonal transformation was performed to convert the original data, in this case, the answers, into a new set of uncorrelated variables, PCs, so that the first few PCs retain most of the variation present in all of the data set. The PCs with the most significant exploratory power were exploited as dependent variables, the socio-economic attributes were used as independent variables, and the information of knowledge about video surveillance systems were used as control variables.

Prior to the regression analysis, we performed a Kaiser-Meyer-Olkin (KMO) test [50] and Bartlett's Test of Sphericity [51] to verify whether the data acquired from the returned questionnaires was suitable for factor analysis. In addition, we also calculated the anti-image correlation matrix of the responses to the questions of the third section and the Measure of Sample Adequacy (MSA) of each Likert scaling was obtained.

\section{Results}

\subsection{Descriptive Statistics of Survey Results}

The total number of validly returned questionnaires was 1080 and the average completion time was $140.5 \mathrm{~s}$. The demographic information of the respondents is shown in Figure 1. Among the 1080 effective questionnaires returned, there is a bias in the sample toward $20-35$ y old (49.9\%), technical or bachelor degree (51.1\%), medium income (3500-10,000 RMB per month) (39.6\%) respondents who work in other professions (36.8\%), and have lived in Beijing for over ten years (39.7\%). We reviewed the correlations within the demographic composition using Pearson correlation coefficient (PCC), a statistical metric which measures the strength and direction of a linear relationship between two random variables (Rodgers and Nicewander, 1988). According to the results of PCC analysis, only pairs of demographic variables, age and income, age and occupation, and income and occupation, show some moderate correlations over 0.5 , while no other link can be observed elsewhere; similar to the survey results of waste disposal behaviors [34]. This indicates that there is no noticeable bias in the samples. 


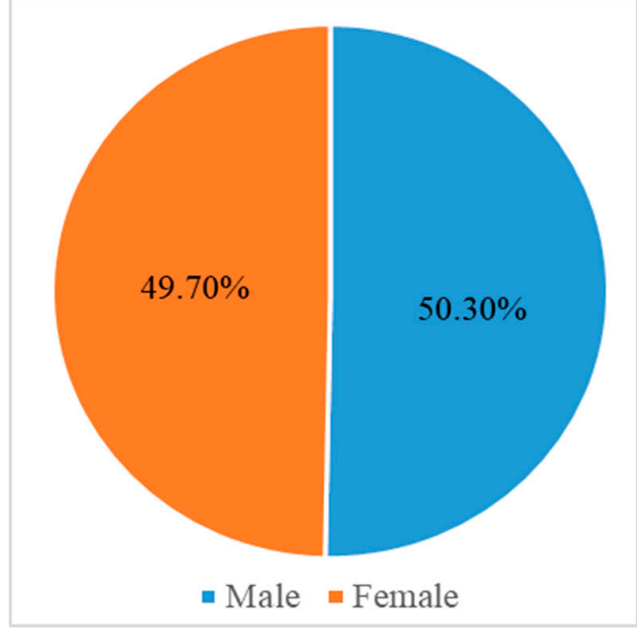

(a) Gender

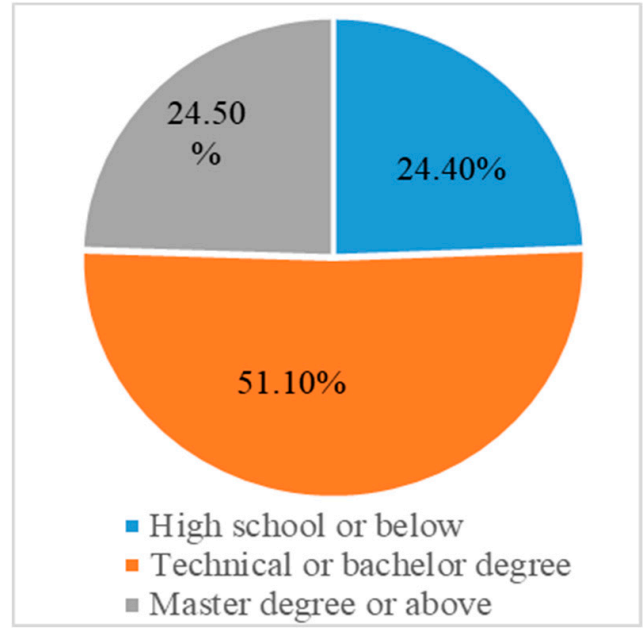

(c) Level of education

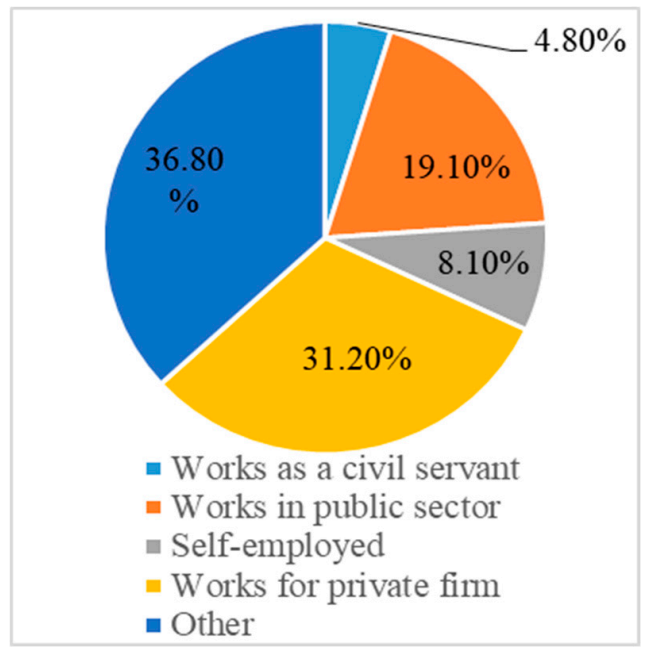

(e) Occupation

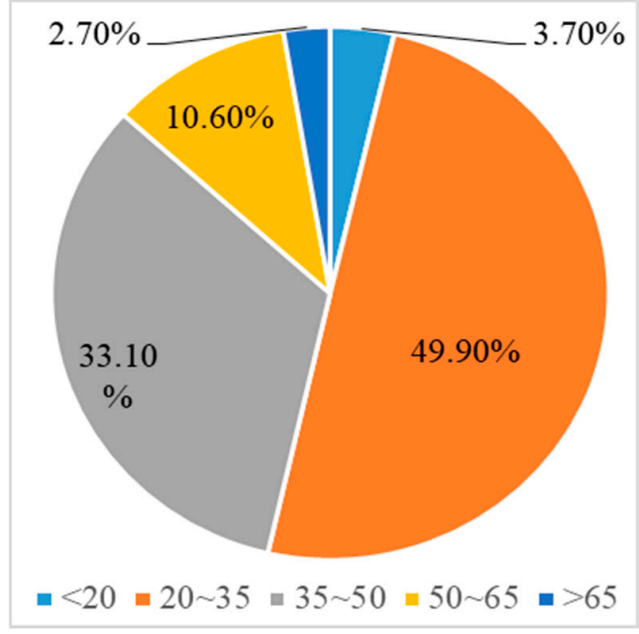

(b) Age

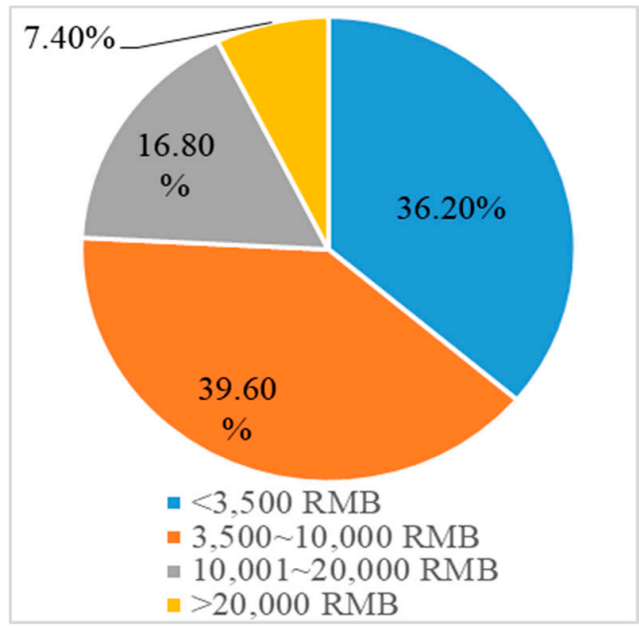

(d) Income level (RMB per month)

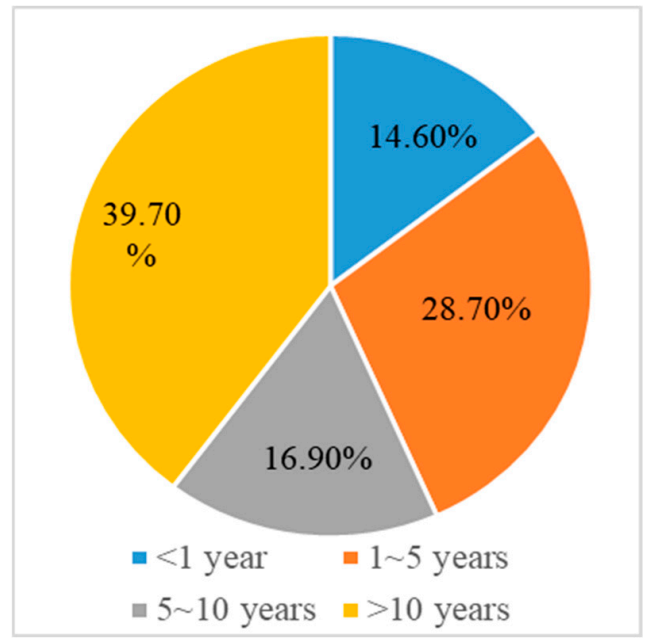

(f) Time of residence in Beijing

Figure 1. Socioeconomic characteristics of the respondents: (a) gender, (b) age, (c) level of education, (d) income level (RMB per month), (e) occupation, and (f) time of residence in Beijing. 
The respondents' knowledge on video surveillance systems is summarized in Figure 2. Although most of the respondents reported that they have contacted surveillance systems in daily life, fewer people have handled the systems or possess the sophisticated knowledge of such systems.

The descriptive statistics of the answers to the questions of perceptions and attitudes towards video surveillance systems are shown in Table 2. In general, the respondents agree that the presence of video surveillance systems can reduce crimes (Q10) and accidents (Q11), as well as promote perceived safety (Q13). Specifically, the respondents are in favor of routes with video surveillance systems (Q13), and the high scores and the low standard deviation imply the strong preference. The respondents are generally neutral about the claim that the video surveillance systems would impose psychological pressure on people. A detailed review on the effects of socio-economic characteristics is presented in the next subsection.

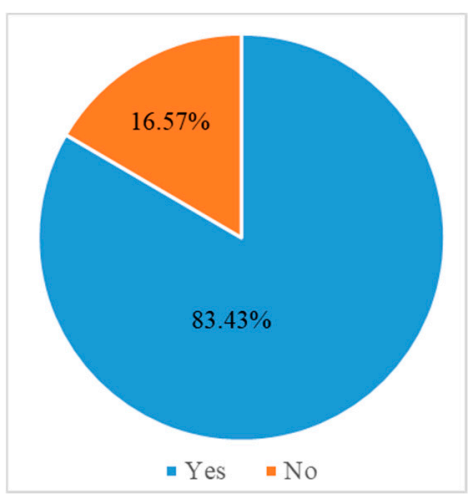

(a) Q7 (cil)

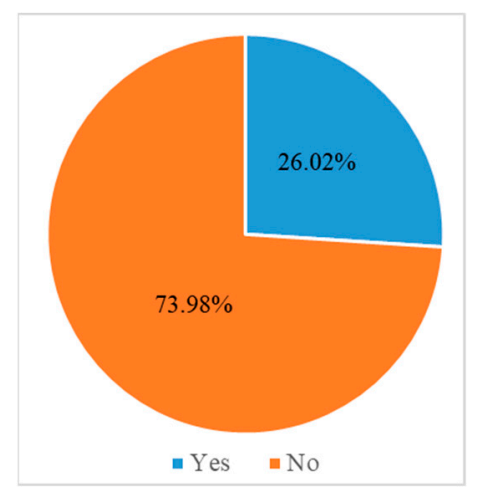

(b) Q8 (ciw)

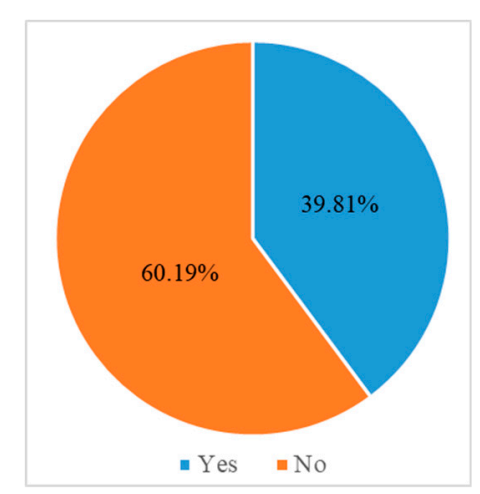

(c) Q9 (kno)

Figure 2. The respondents' knowledge on video surveillance systems: (a) whether they contact video surveillance systems in life (Q7), (b) whether they handle video surveillance systems in work (Q8), and (c) do they have knowledge about the structure and operation of video surveillance systems (Q9).

Table 2. Descriptive statistics of the answers to the questions of perceptions and attitudes towards video surveillance systems.

\begin{tabular}{cccc}
\hline Question & Observations (Obs.) & Mean & Standard Deviation (Std.) \\
\hline Q10 (cri) & 1080 & 4.29 & 0.926 \\
Q11 (acc) & 1080 & 4.08 & 1.048 \\
Q12 (eno) & 1080 & 3.31 & 1.228 \\
Q13 (saf) & 1080 & 4.16 & 1.074 \\
Q14 (cho) & 1080 & 4.44 & 0.857 \\
Q15 (cau) & 1080 & 3.75 & 1.223 \\
Q16 (pre) & 1080 & 3.05 & 1.384 \\
Q17 (enh) & 1080 & 3.84 & 1.208 \\
Q18 (wor) & 1080 & 3.98 & 1.094 \\
\hline
\end{tabular}

\subsection{Results of Univariate Analysis}

\subsubsection{Effects of Gender}

The effects of gender on the answers to the questions of perceptions and attitudes towards video surveillance systems are shown in Figure 3. As shown in Figure 3, different from the findings of Brown [12] and Johnson et al. [13], the female respondents' perceptions of safety of video surveillance cameras are higher than those of the male respondents, particularly in terms of crime reduction (Q10). Compared to the self-reports of the male respondents, the female respondents prefer housings (Q13) and routes (Q14) with video surveillance cameras and feel more comfortable under the presence of such systems, that is, there is less perceived pressure (Q16) and they do not become more cautious (Q17). Moreover, the female respondents are more likely to agree that the existence of video surveillance 
cameras is vital to public security (Q18). In sum, the survey results indicate that female residents exhibit a higher perceived safety, acceptance, and support for video surveillance cameras and the differences between males and females are quite significant.

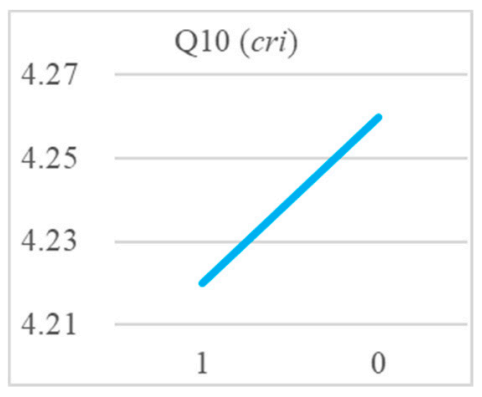

(a) Results of Q10 (cri) *

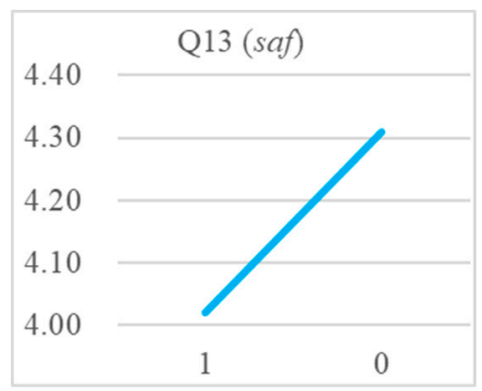

(d) Results of Q13 (saf) ***

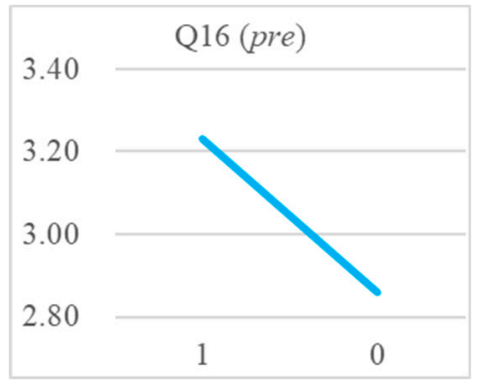

(g) Results of Q16 (pre) ***

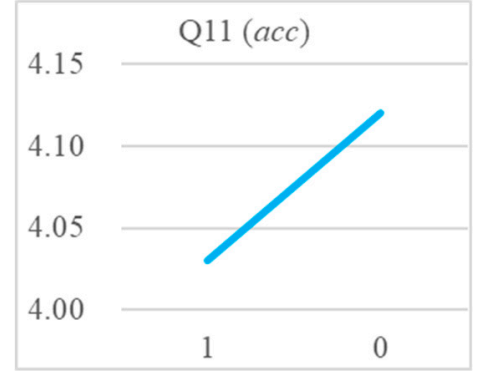

(b) Results of Q11 (acc)

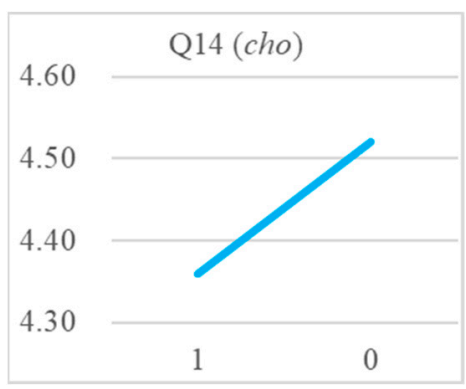

(e) Results of Q14 (cho) **

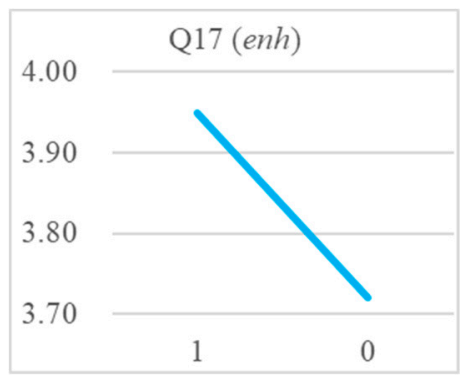

(h) Results of Q17 (enh) **

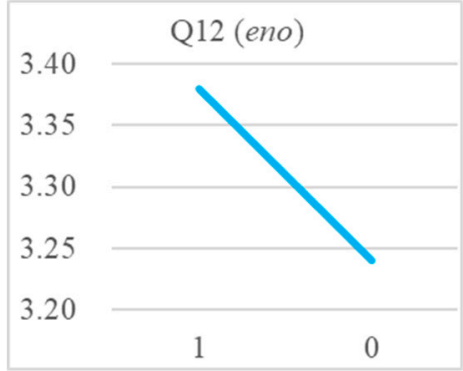

(c) Results of Q12 (eno)

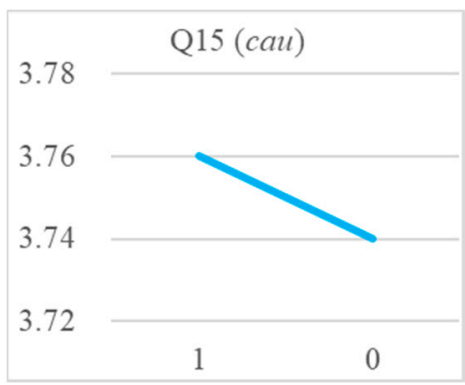

(f) Results of Q15 (cau)

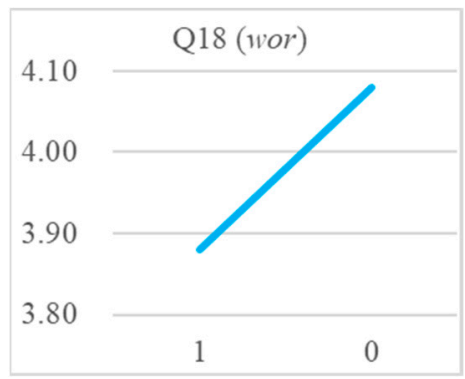

(i) Results of Q18 (wor) **

Figure 3. The effects of gender on the outcomes of (a) Q10, (b) Q11, (c) Q12, (d) Q13, (e) Q14, (f) Q15, (g) Q16, (h) Q17, and (i) Q18. Note: ***, and *** denote significance at 5\%, $1 \%$, and $0.1 \%$ levels, respectively. Note that different scales of $y$-axis are used in the plots, therefore the trend slopes are non-comparable; the figures only demonstrate the directions (increasing/decreasing) associated with the attributes.

\subsubsection{Effects of Age}

The effects of age on the answers to the questions of perceptions and attitudes towards video surveillance systems are shown in Figure 4. Figure 4 shows that, compared to the young and middle-aged respondents, the elder respondents perceive less safety in terms of crime reduction (Q10) and feel that there are sufficient video surveillance systems (Q12). The elder respondents also show less preference towards housings (Q13) and routes (Q14) with video surveillance systems, probably because they are more stressed with the presence of such systems (Q16) than the young and middle-aged respondents. In sum, the survey results show that senior residents might not be very supportive and adoptive to video surveillance systems. 


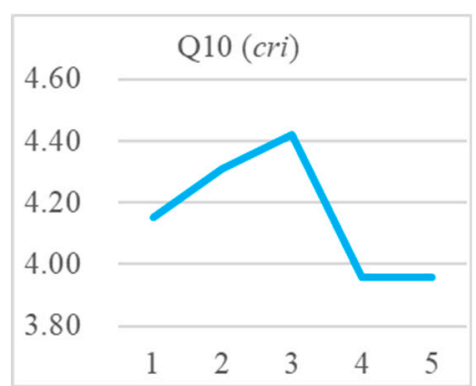

(a) Results of Q10 (cri) ${ }^{* * *}$

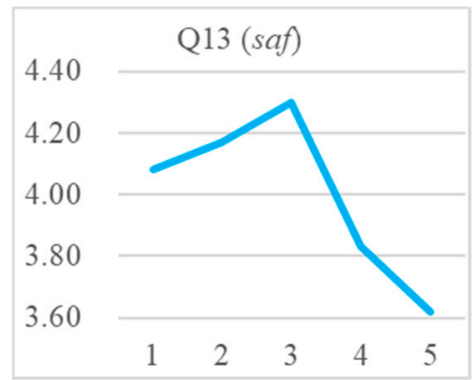

(d) Results of Q13 (saf) ***

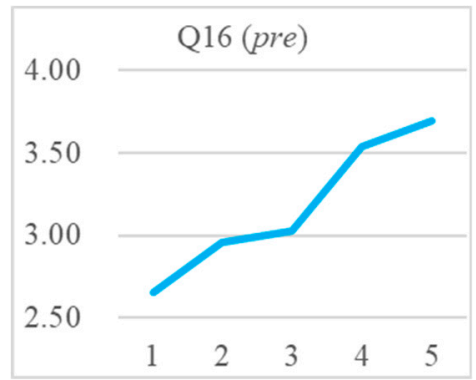

(g) Results of Q16 (pre) ***

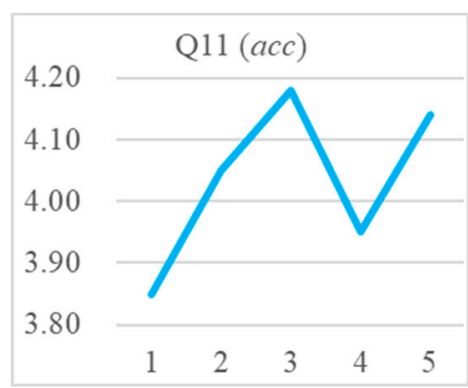

(b) Results of Q11 (acc)

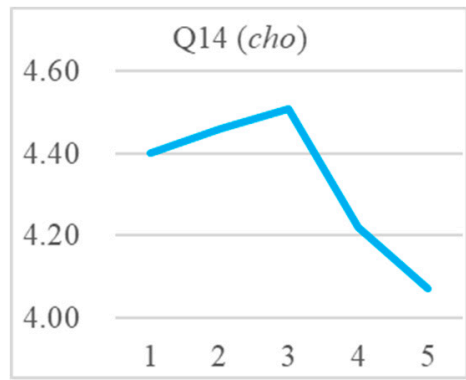

(e) Results of Q14 (cho) **

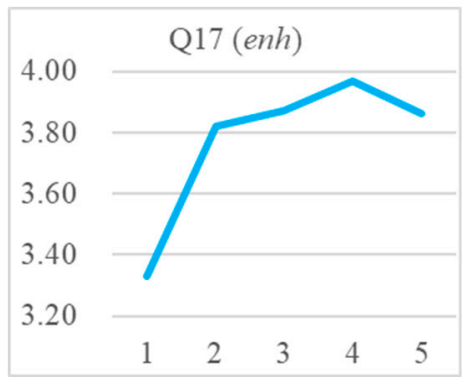

(h) Results of Q17 (enh)

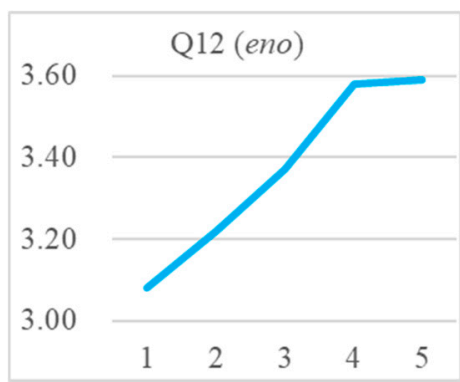

(c) Results of Q12 (eno) *

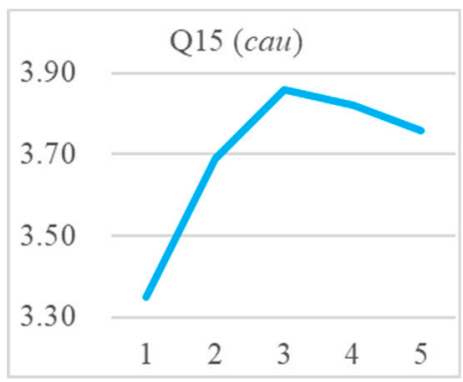

(f) Results of Q15 (cau)

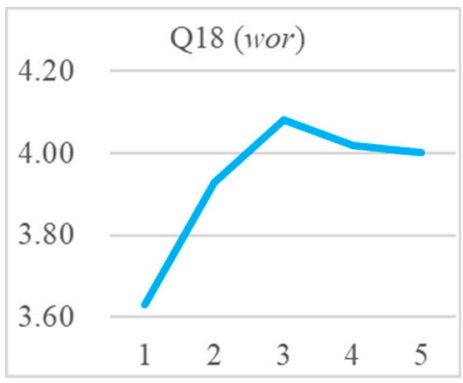

(i) Results of Q18 (wor)

Figure 4. The effects of age on the outcomes of (a) Q10, (b) Q11, (c) Q12, (d) Q13, (e) Q14, (f) Q15, (g) Q16, (h) Q17, and (i) Q18. Note: *,**, and *** denote significance at 5\%, 1\%, and 0.1\% levels, respectively. Note that different scales of $y$-axis are used in the plots, therefore the trend slopes are non-comparable; the figures only demonstrate the directions (increasing/decreasing) associated with the attributes.

\subsubsection{Effects of Education}

The effects of education on the answers to the questions of perceptions and attitudes towards video surveillance systems are shown in Figure 5. The highly educated respondents' perceptions of the safety of video surveillance systems are higher than those of the less educated respondents, specifically in terms of crime reduction (Q10). Additionally, the highly educated respondents feel less stressed with the presence of surveillance systems (Q16). Yet, with higher levels of education received, the respondents $(\mathrm{Q} 18)$ are less likely to strongly agree that the reduction of video surveillance systems could worsen public security (Q18). 


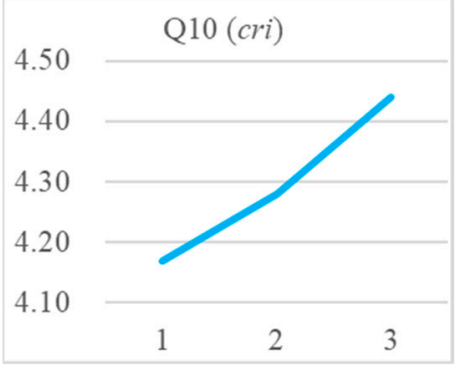

(a) Results of Q10 (cri) **

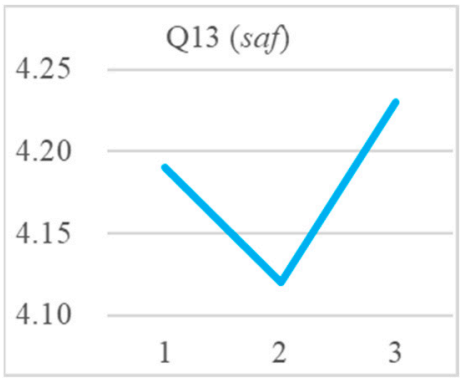

(d) Results of Q13 (saf)

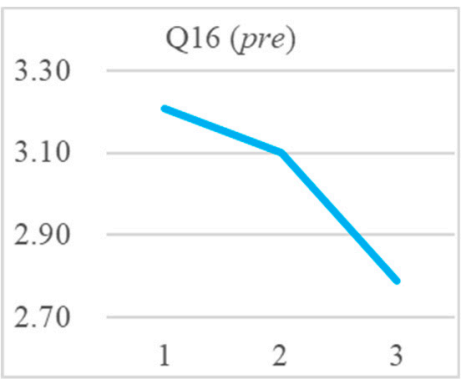

(g) Results of Q16 (pre) ***

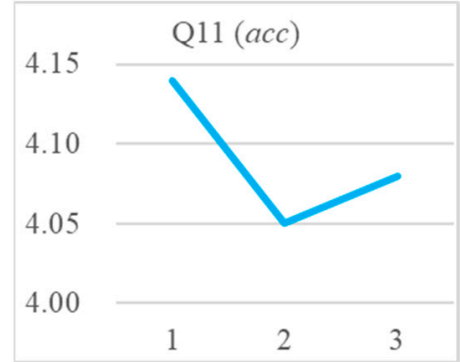

(b) Results of Q11 (acc)

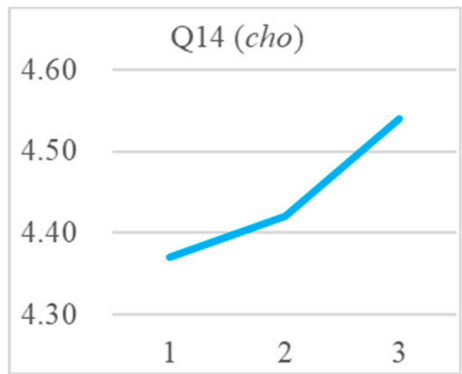

(e) Results of Q14 (cho)

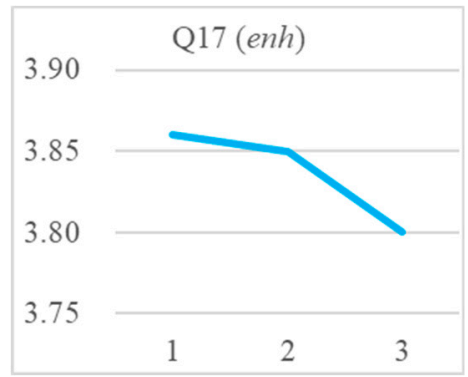

(h) Results of Q17 (enh)

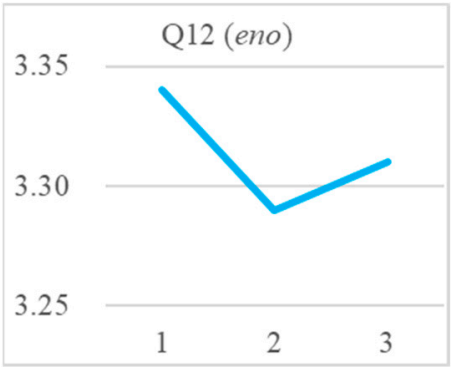

(c) Results of Q12 (eno)

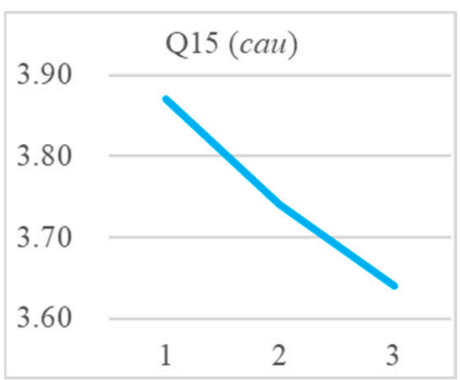

(f) Results of Q15 (cau)

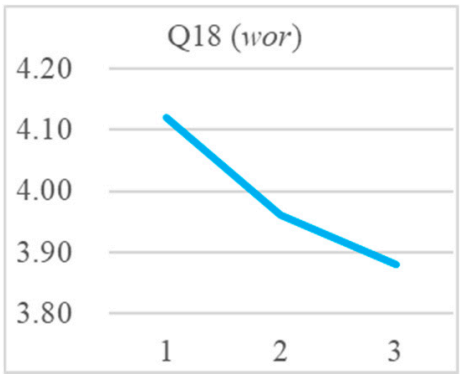

(i) Results of Q18 (wor) *

Figure 5. The effects of education on the outcomes of (a) Q10, (b) Q11, (c) Q12, (d) Q13, (e) Q14, (f) Q15, (g) Q16, (h) Q17, and (i) Q18. Note: *,**, and *** denote significance at 5\%, 1\%, and 0.1\% levels, respectively. Note that different scales of $y$-axis are used in the plots, therefore the trend slopes are non-comparable; the figures only demonstrate the directions (increasing/decreasing) associated with the attributes.

\subsubsection{Effects of Income}

The effects of income on the answers to the questions of perceptions and attitudes towards video surveillance systems are shown in Figure 6. In general, as shown in Figure 6, the respondents' perceived safety of crime reduction (Q10) and preferences of residences (Q13) and roads (Q14) with surveillance systems decreases with their increasing level of monthly incomes, while their likelihood of believing video surveillance is sufficient (Q12) and perceived psychological pressure (Q16 and Q17) is increased. This implies that the high-income respondents general show a negative attitude towards video surveillance systems. However, the group of respondents with the highest income level tend to be more positive towards video surveillance systems, when compared to the attitude of the previous group, that is, the respondents with an income of 10,001 to 20,000 RMB per month. 


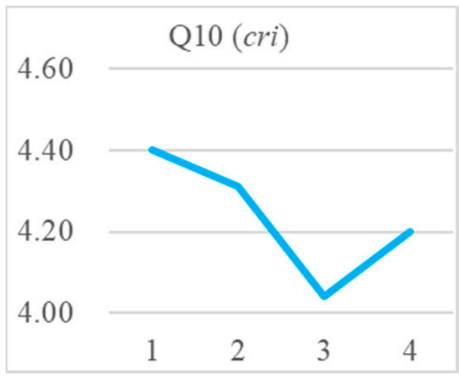

(a) Results of Q10 (cri) ***

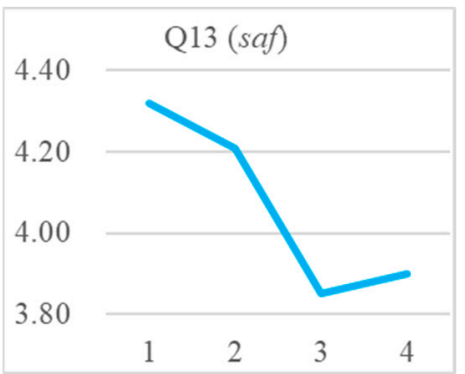

(d) Results of Q13 (saf) ***

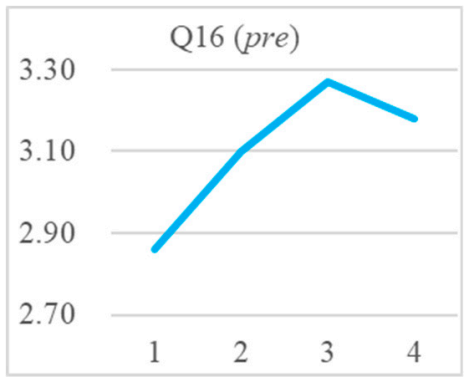

(g) Results of Q16 (pre) **

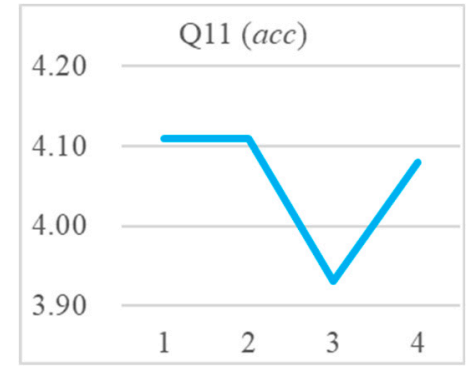

(b) Results of Q11 (acc)

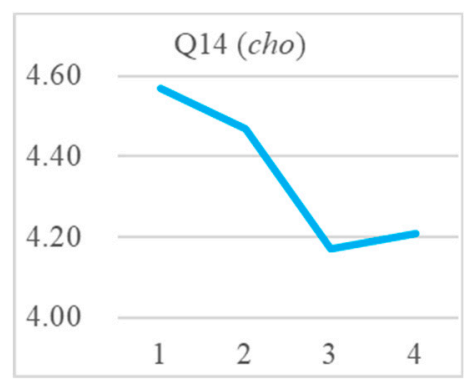

(e) Results of Q14 (cho) ***

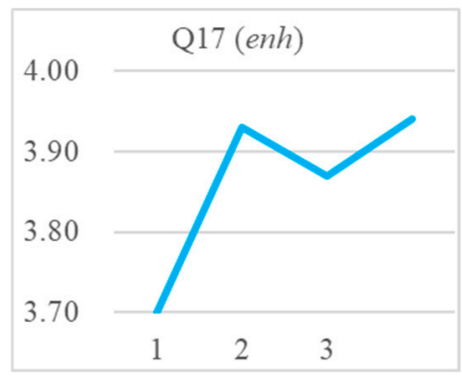

(h) Results of Q17 (enh) *

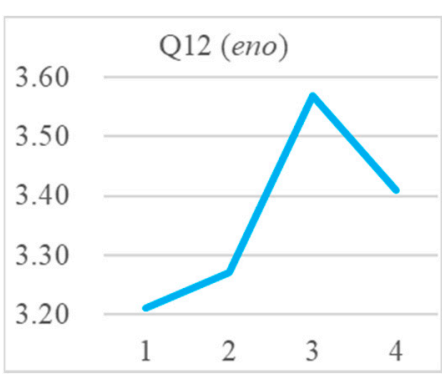

(c) Results of Q12 (eno) **

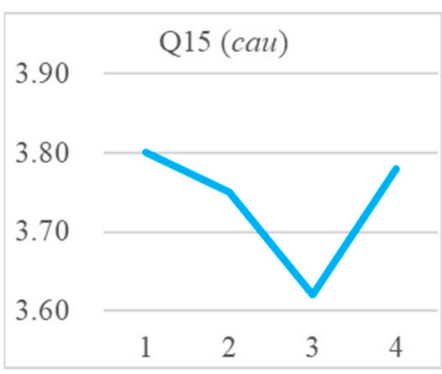

(f) Results of Q15 (cau)

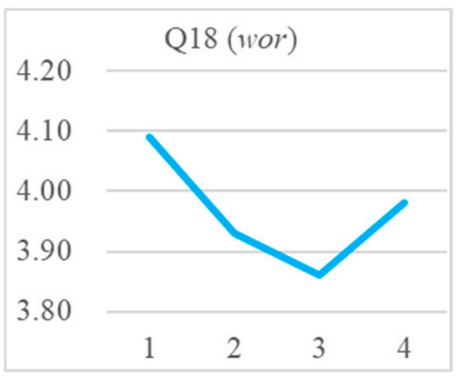

(i) Results of Q18 (wor)

Figure 6. The effects of monthly income on the outcomes of (a) Q10, (b) Q11, (c) Q12, (d) Q13, (e) Q14, (f) Q15, (g) Q16, (h) Q17, and (i) Q18. Note: ****, and *** denote significance at 5\%, $1 \%$, and $0.1 \%$ levels, respectively. Note that different scales of $y$-axis are used in the plots, therefore the trend slopes are non-comparable; the figures only demonstrate the directions (increasing/decreasing) associated with the attributes.

\subsubsection{Effects of Occupation}

The effects of occupation on the answers to the questions of perceptions and attitudes towards video surveillance systems are shown in Figure 7. Surprisingly, as shown in Figure 7, the respondents from governments and private enterprises are more negative about video surveillance systems, as they perceive the least level of safety in terms of crime reduction (Q10), are more likely to believe the current quantity of surveillance systems is sufficient (Q12), show less preferences to housings (Q13) and roads (Q14) with surveillance systems, and are more distressed with the presence of video surveillance systems (Q16). The respondents of other sectors are the most positive about video surveillance systems, confirmed by the highest perceived safety of reducing crimes $(\mathrm{Q} 10)$, the highest preferences to residences (Q13) and roads (Q14) with surveillance systems, and the least self-reported pressure imposed by such systems (Q16 and Q17). The self-employed respondents firmly believe that the public security would be worsened provided that there are less surveillance systems (Q18). 


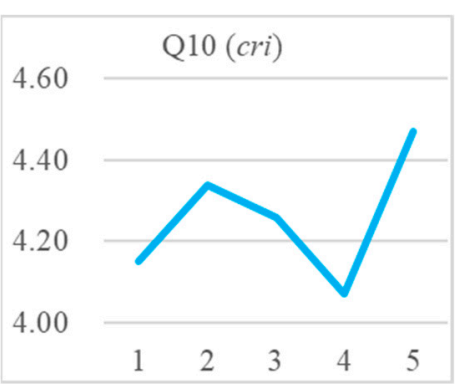

(a) Results of Q10 (cri) ***

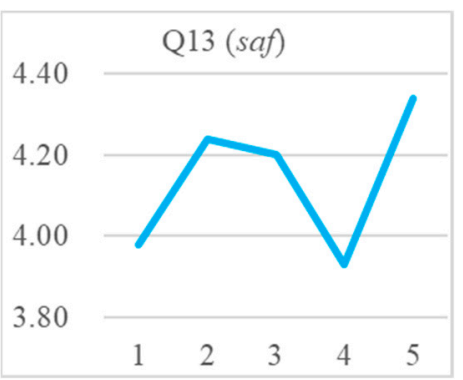

(d) Results of Q13 (saf) ***

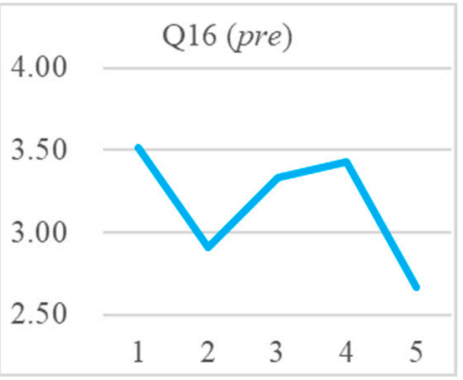

(g) Results of Q16 (pre) ***

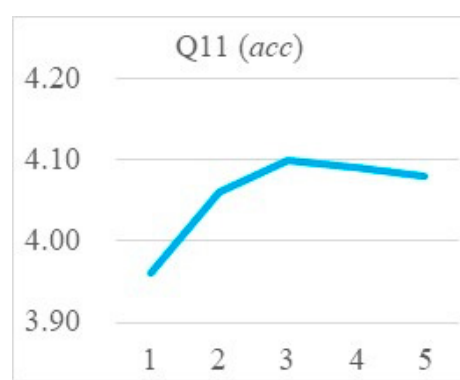

(b) Results of Q11 (acc)

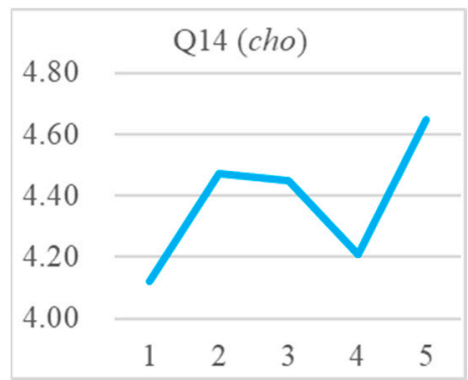

(e) Results of Q14 (cho) ***

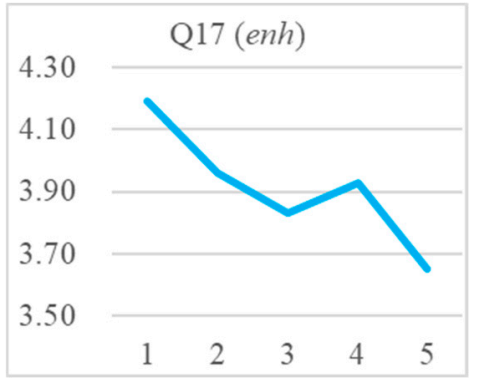

(h) Results of Q17 (enh) ***

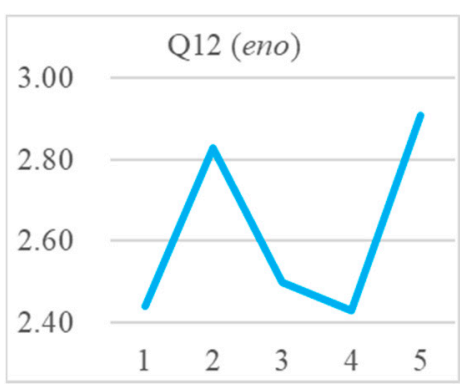

(c) Results of Q12 (eno) ***

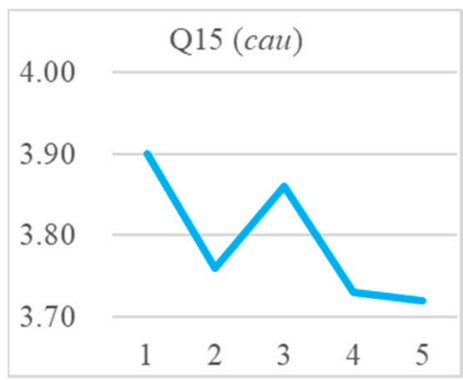

(f) Results of Q15 (cau)

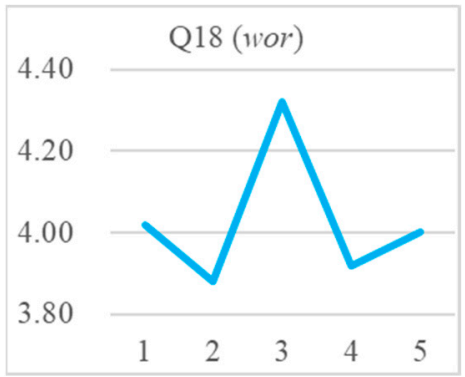

(i) Results of Q18 (wor) *

Figure 7. The effects of occupation on the outcomes of (a) Q10, (b) Q11, (c) Q12, (d) Q13, (e) Q14, (f) Q15, (g) Q16, (h) Q17, and (i) Q18. Note: * **, and *** denote significance at 5\%, $1 \%$, and $0.1 \%$ levels, respectively. Note that different scales of $y$-axis are used in the plots, therefore the trend slopes are non-comparable; the figures only demonstrate the directions (increasing/decreasing) associated with the attributes.

\subsubsection{Effects of Residence}

The effects of residence on the answers to the questions of perceptions and attitudes towards video surveillance systems are shown in Figure 8. From Figure 8, the longer length of residence in the studied city, Beijing, could clearly facilitate the adoption of video surveillance systems. The respondents who lived in Beijing for over ten years exhibit the greatest perceived safety in terms of crime reduction (Q10), the highest preferences to residences (Q13) and roads (Q14) with surveillance systems, and feel the least pressure with the presence of video surveillance systems (Q16). Moreover, this group of respondents also less likely to strongly agree that the current surveillance systems are sufficient (Q12). Clearly, longer residence promotes the personal acceptance and support of video surveillance. 


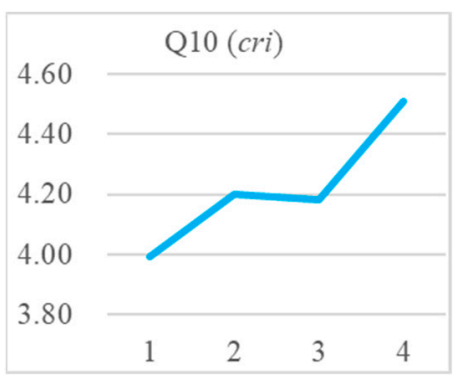

(a) Results of Q10 (cri) ${ }^{* * *}$

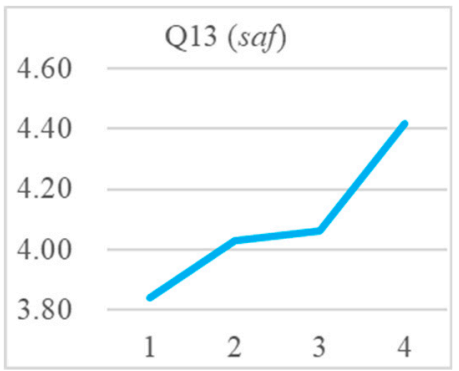

(d) Results of Q13 (saf) ***

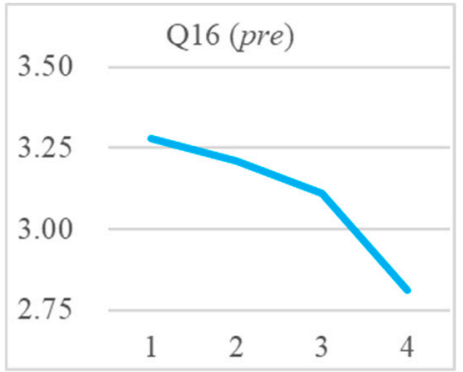

(g) Results of Q16 (pre) ***

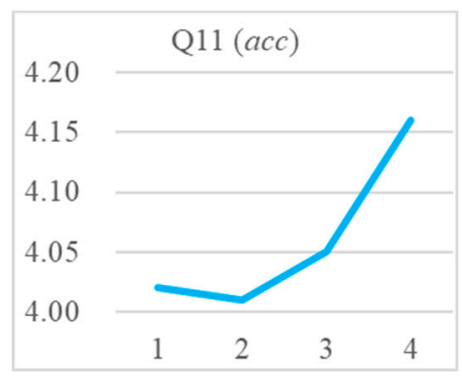

(b) Results of Q11 (acc)

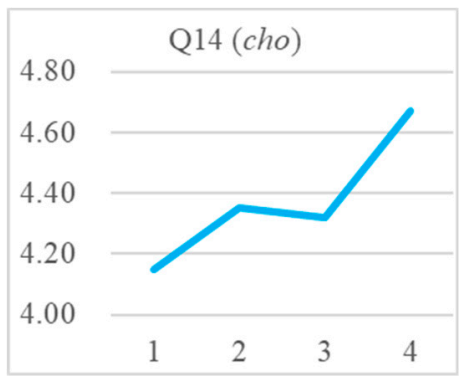

(e) Results of Q14 (cho) ${ }^{* * *}$

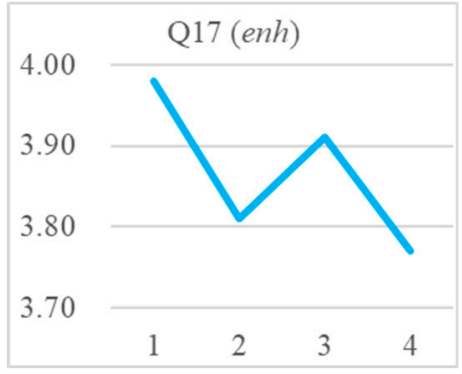

(h) Results of Q17 (enh)

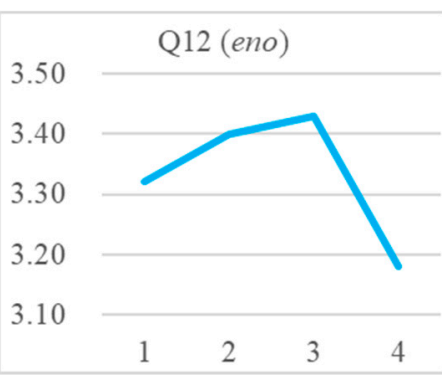

(c) Results of Q12 (eno) *

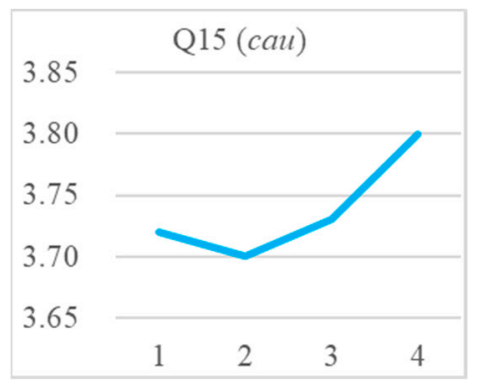

(f) Results of Q15 (cau)

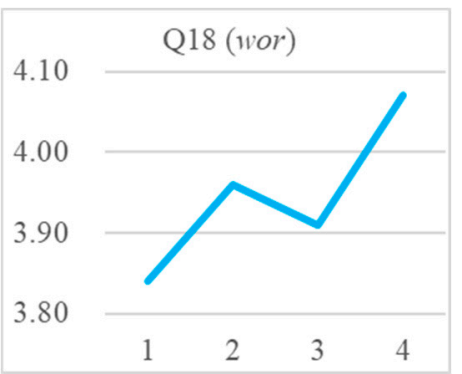

(i) Results of Q18 (wor)

Figure 8. The effects of residence on the outcomes of (a) Q10, (b) Q11, (c) Q12, (d) Q13, (e) Q14, (f) Q15, (g) Q16, (h) Q17, and (i) Q18. Note: *,**, and *** denote significance at 5\%, 1\%, and $0.1 \%$ levels, respectively. Note that different scales of $y$-axis are used in the plots, therefore the trend slopes are non-comparable; the figures only demonstrate the directions (increasing/decreasing) associated with the attributes.

\subsection{Results of Regression Analysis}

Based on the original survey data, the KMO result is 0.807 and Bartlett's $p=0.000<0.05$, indicating that univariate analysis is applicable for the data. The anti-image correlation matrix of the survey responses is shown in Table 3, in which all the MSA values are greater than 0.7 , confirming that the data is applicable for factor analysis.

Based on PCA calculation, the first two PCs are taken, because they explain over most of variation (over 80\%). The correlations between the selected PCs and the answers to the questions of perceptions and attitudes towards video surveillance systems are shown as the following equations: 


$$
\begin{gathered}
F_{1}=0.244 c r i+0.266 a c c+0.047 \text { eno }+0.340 \text { saf }+0.197 \text { cho }+0.115 c a u-0.231 \text { pre }-0.007 \text { enh }+0.241 \text { wor } \\
F_{2}=-0.057 c r i+0.003 a c c-0.264 \text { eno }-0.092 \text { saf }-0.033 c h o+0.240 c a u+0.538 p r e+0.279 e n h+0.030 w o r
\end{gathered}
$$

where $F_{1}$ and $F_{2}$ denote the first and the second extracted PC, respectively. Furthermore, we reduce the PCs to ensure that each and every of the parameterized questions of perceptions and attitudes towards video surveillance systems is only loaded on one PC, the one with higher coefficient is kept, shown as follows:

$$
\begin{gathered}
F_{1}{ }^{\prime}=0.244 c r i+0.266 a c c+0.340 \text { saf }+0.197 \text { cho }+0.241 \text { wor } \\
F_{2}{ }^{\prime}=-0.264 \text { eno }+0.240 \text { cau }+0.538 p r e+0.279 \text { enh }
\end{gathered}
$$

where $F_{1}{ }^{\prime}$ and $F_{2}{ }^{\prime}$ denote the first and the second reduced PC, respectively. With this particular process, the reduced PCs are endowed with actual meanings as follows: The first PC represents the perceived safety and behavioral preferences of the respondents and the second one denotes the attitudes of the respondents towards video surveillance systems. Consistent with the design of the questionnaire (see Section 3.1), the higher value of the 1st PC and the lower value of the 2nd PC would imply the favor towards video surveillance systems. Before employing personal characteristics in regression analysis, the PCCs between demographic features, knowledge about video surveillance systems, and the two reduced PCs are calculated using the classical procedure [52]. The PCC values are shown in Table 4, in which the linkages of the other pairs of the parameters are presented with their significance.

\begin{tabular}{|c|c|c|c|c|c|c|c|c|c|c|c|}
\hline & $\operatorname{sex}$ & age & $e d u$ & inc & job & year & cil & $c i w$ & kno & $F_{1}^{\prime}$ & $F_{2}^{\prime}$ \\
\hline $\operatorname{sex}$ & 1 & -0.015 & $-0.093 * *$ & $-\underset{* * *}{0.139}$ & 0.061 * & $0.150 * * *$ & 0.040 & $0.135^{* * *}$ & $0.151^{* * *}$ & 0.048 & $-0.111^{* * *}$ \\
\hline age & & 1 & $-0.174 * *$ & $0.181^{* * *}$ & $-0.240 * *$ & $0.191^{* * *}$ & -0.018 & $-0.207^{* * *}$ & $-0.219^{* * *}$ & 0.015 & $0.106^{* * *}$ \\
\hline edu & & & 1 & $0.149^{* * *}$ & -0.028 & 0.002 & -0.044 & $0.212 * * *$ & $0.110^{* * *}$ & -0.005 & -0.096 ** \\
\hline inc & & & & 1 & $-0.293 * *$ & 0.028 & $-0.068 *$ & $-0.183^{* * *}$ & $-0.246^{* * *}$ & $-0.080 * *$ & 0.055 \\
\hline job & & & & & 1 & $-0.111^{* * *}$ & -0.018 & $0.160^{* * *}$ & $0.166^{* * *}$ & 0.006 & $-0.101^{* * *}$ \\
\hline year & & & & & & 1 & $-0.077^{*}$ & $0.184^{* * *}$ & $0.120 * * *$ & $0.124^{* * *}$ & $-0.084 * *$ \\
\hline cil & & & & & & & 1 & 0.000 & 0.022 & -0.010 & 0.029 \\
\hline ciw & & & & & & & & 1 & $-0.421 * *$ & $0.115^{* * *}$ & $-0.105^{* * *}$ \\
\hline kno & & & & & & & & & 1 & $-0.085^{* *}$ & $-0.132 * * *$ \\
\hline$F_{1}^{\prime}$ & & & & & & & & & & 1 & $0.511^{* * *}$ \\
\hline$F_{2}^{\prime}$ & & & & & & & & & & & 1 \\
\hline
\end{tabular}

Table 3. Anti-image correlation matrix of the survey data.

\begin{tabular}{cccccccccc}
\hline & cri & acc & eno & saf & cho & cau & pre & enh & wor \\
\hline cri & $0.796^{*}$ & -0.353 & 0.065 & -0.304 & -0.343 & -0.003 & 0.078 & 0.001 & -0.021 \\
acc & -0.353 & $0.849^{*}$ & 0.056 & -0.046 & -0.014 & -0.043 & -0.119 & 0.043 & -0.121 \\
eno & 0.065 & 0.056 & $0.809^{*}$ & -0.003 & 0.020 & 0.073 & 0.305 & 0.004 & -0.013 \\
saf & -0.304 & -0.046 & -0.003 & $0.848^{*}$ & -0.272 & -0.104 & 0.127 & -0.018 & -0.142 \\
cho & -0.343 & -0.014 & 0.020 & -0.272 & $0.838^{*}$ & -0.143 & 0.087 & -0.044 & -0.208 \\
cau & -0.003 & -0.043 & 0.073 & -0.104 & -0.143 & $0.850 *$ & -0.299 & -0.237 & -0.103 \\
pre & 0.078 & -0.119 & 0.305 & 0.127 & 0.087 & -0.299 & $0.683 *$ & -0.324 & -0.048 \\
enh & 0.001 & 0.043 & 0.004 & -0.018 & -0.044 & -0.237 & -0.324 & $0.808^{*}$ & -0.163 \\
wor & -0.021 & -0.121 & -0.013 & -0.142 & -0.208 & -0.103 & -0.048 & -0.163 & $0.899^{*}$ \\
\hline \multicolumn{7}{c}{ Note: * MSA- Measure of Sample Adequacy. }
\end{tabular}

Table 4. Pearson correlation matrix of the attributes and the factors.

Note: ${ }^{*}, * *$ and ${ }^{* * *}$ denote significance at $5 \%, 1 \%$, and $0.1 \%$ levels, respectively. 
From Table 4, at the significance of $1 \%$ level, $F_{1}{ }^{\prime}$ is significantly correlated to inc, year, ciw, kno and $F_{2}{ }^{\prime}$, and $F_{2}{ }^{\prime}$ is significantly correlated to sex, age, edu, job, year, ciw, kno and $F_{1}{ }^{\prime}$. Therefore, the regression models are constructed as follows:

$$
\begin{gathered}
F_{1}^{\prime}=a_{11}+a_{12} \cdot \text { inc }+a_{13} \cdot \text { year }+a_{14} \cdot \text { ciw }+a_{15} \cdot k n o \\
F_{2}^{\prime}=a_{21}+a_{22} \cdot \operatorname{sex}+a_{23} \cdot \text { age }+a_{24} \cdot e d u+a_{25} \cdot j o b+a_{26} \cdot \text { year }+a_{27} \cdot \text { ciw }+a_{28} \cdot k n o
\end{gathered}
$$

where both the reduced PCs are dependent variables, $a_{i j}$ are coefficients, the personal characteristics are employed as independent variables, and the self-reported knowledge about video surveillance systems are used as control variables.

The regression results are shown in Table 5. In general, the results of the regression analysis are consistent with the results of the univariate analysis, as the influential factors, such as gender and length of residence, affect the perceived safety, preferences, and attitudes towards video surveillance systems. As shown in Table 5 , the perceived safety and behavioral preferences of the respondents $\left(F_{1}{ }^{\prime}\right)$ are negatively correlated to the level of monthly income, while the values are positively correlated to the length of residence in Beijing. Additionally, the experience with video surveillance systems in life also positively affects the perceived safety and behavioral preferences. Amongst the three parameters, the most significant factor is the length of residence, indicating that, from Table 5 at the $1 \%$ significance level, the attitudes of the respondents towards video surveillance systems $\left(F_{2}{ }^{\prime}\right)$ are significantly correlated to gender, level of education, and length of residence. The female respondents, highly-educated respondents, and long-term residents of Beijing are more accustomed to the presence of video surveillance systems. At the 5\% significance level, growing in age imparts more psychological stress on the respondents, making the aged people feel uneasy about surveillance, while the self-reported knowledge about such systems (knowing the structure and operation of surveillance systems) tends to comfort the respondents.

Table 5. Results of the parameters in Model (1) and Model (2).

\begin{tabular}{ccccc}
\hline \multicolumn{5}{c}{ Model (1) } \\
\hline Variable & Coefficient & Stand Error & T-statistic & Pr. \\
\hline Constant & 11.557 & 0.376 & 30.766 & $0.000^{* * *}$ \\
inc & -0.153 & 0.075 & -2.039 & $0.042^{*}$ \\
year & 0.215 & 0.060 & 3.576 & $0.000^{* * *}$ \\
ciw & 0.355 & 0.166 & 2.133 & $0.033^{*}$ \\
kno & 0.117 & 0.150 & 0.779 & 0.436 \\
\hline \multicolumn{5}{c}{ Model (2) } \\
\hline Variable & Coefficient & Stand Error & T-statistic & Pr. \\
\hline Constant & 3.758 & 0.249 & 15.098 & $0.000^{* * *}$ \\
sex & -0.187 & 0.064 & -2.907 & $0.004^{* *}$ \\
age & 0.090 & 0.041 & 2.186 & $0.029^{*}$ \\
edu & -0.128 & 0.047 & -2.739 & $0.006^{* *}$ \\
job & -0.065 & 0.026 & -2.507 & $0.012^{*}$ \\
year & -0.080 & 0.030 & -2.660 & $0.008^{* *}$ \\
ciw & -0.007 & 0.082 & -0.082 & 0.935 \\
kno & -0.148 & 0.072 & -2.059 & $0.040^{*}$ \\
\hline
\end{tabular}

Note: ${ }^{*},{ }^{*}$, and ${ }^{* * *}$ denote significance at $5 \%, 1 \%$, and $0.1 \%$ levels, respectively.

\section{Discussion}

\subsection{Shortcomings}

We acknowledge that the major limitation of the current contribution lies in the scope of research. The study focuses on only surveying the residents in Beijing to understand the impacts of video 
surveillance systems the perceptions of safety and behavioral preferences, as well as to acquire the attitudes towards such systems. Although Beijing is a city of sophisticated surveillance systems [23] and a highly populated city, the survey data is not representative for a large-scale population. Therefore, the results are not universally applicable to every other city in the world. However, to survey a broader range of population, more desirable residents from different cities in different countries across the globe, poses an extremely difficult challenge. Additionally, considering the fact that heterogenous video surveillance systems are implemented in different cities and countries, the creditability of such a large-scale survey could be highly questionable.

\subsection{Implications}

Despite the above limitation, several recommendations are provided to ensure the sustainability of video surveillance systems, on the basis the results and analysis that are presented in the previous section.

First, video surveillance systems should be implemented in the housings and regions with more potential supporters of such systems, such as females, young people, educated residents, low income earners, and long-term citizens. From the above results, these groups show higher acceptance and support to surveillance and, most likely, these people may lay more emphasis on security than other groups of residents.

Second, it is important to popularize the knowledge regarding the structure and operation of surveillance systems, because this piece of knowledge would ease the psychological tension that is possibly imposed by the presence of surveillance systems, as shown in Table 5, i.e., the results of the regression analysis.

Due to the rapid expansion of higher education in China [53] and its positive impacts on urbanization [54], Chinese residents' acceptance and support of surveillance are expected to increase in the foreseeable future. Yet, technical measures and legal regulations that aim at privacy protection [20] are still in need of attention and efforts.

\section{Conclusions}

In this study, we investigated the factors that influence the perception of safety, behavior preferences, and attitudes towards video surveillance systems, based on a questionnaire-based survey on residents in Beijing, China. Univariate analysis and regression analysis were employed to analyze the 1080 validly returned surveys. We observed that gender, level of education, and length of residence significantly affect the perceived safety of surveillance systems, as female, educated, and long-term residents tend to strongly agree that surveillance systems promote public security. Moreover, these groups of respondents also prefer housings and routes with video surveillance systems and are more accustomed to the systems. However, the elder respondents are more distressed with the presence of video surveillance systems and thereby they perceive less safety for the younger population. Based on the results, we offer several recommendations, such as selective implementation and knowledge popularization to facilitate the adoption and sustainability of such systems.

The potential future research can be carried out in the three following directions. First, a large-scale survey is highly desirable to test the findings of this study, as this work is solely based on the residents in Beijing. Second, field investigation can be included to verify the behavioral preferences of urban residents, as the divergence between behaviors and attitudes requires more attention and detailed explanation. Third, it is valuable to investigate how the personal characteristics affect behaviors, since the self-reported behavioral preferences might not be sufficiently convincing.

Author Contributions: Conceptualization, H.Z. and F.G.; methodology, F.G.; software, C.D. and F.G.; validation, J.G. and F.G.; formal analysis, F.G.; investigation, C.D.; resources, H.Z. and J.G.; data curation, F.G.; writing-original draft preparation, H.Z. and F.G.; writing-review and editing, F.G., J.G., and Y.F.; visualization, C.D.; supervision, J.G. and Y.F.; project administration, J.G. and Y.F.; funding acquisition, J.G. 
Funding: This research was funded by National Natural Science Foundation of China (Grant nos. 71671180 \& 71671180).

Conflicts of Interest: The authors declare no conflict of interest.

\section{Nomenclature}

Abbreviations

A Agree

ANOVA Analysis of variance

D Disagree

KMO Kaiser-Meyer-Olkin

IP Internet Protocol

MSA Measure of Sample Adequacy

NBS National Bureau of Statistics of China

NN Neither disagree nor agree

Obs Observations

PC Principal component

PCA Principal component analysis

PCC Pearson correlation coefficient

SA Strongly agree

SD Strongly disagree

Std Standard deviation

Symbols

$a_{i j} \quad$ Coefficient

acc Video surveillance systems can reduce accidents

age Age

cau Video surveillance systems make people behave more cautious

cho Choose routes with video surveillance systems would be more preferable

cil Whether the respondent contact video surveillance systems in life

ciw Whether the respondent handle video surveillance systems in work

cri Video surveillance systems can reduce crimes

edu Level of education

enh Moving surveillance cameras enhance above perceptions, i.e., caution and pressure

eno Current quantity surveillance cameras are enough

$F_{i} \quad$ Initial principal component

$F_{i}{ }^{\prime} \quad$ Reduced principal component

inc Monthly income, in RMB

kno Whether the respondent possess some knowledge about the structure and operation of

video surveillance systems

job Occupation

pre Video surveillance systems bring pressure on people

saf Residence with video surveillance systems are safer

sex Gender

wor Less or no video surveillance systems would worsen public security

year Time of residence in Beijing

Subscripts

$i \quad$ Counter

j Counter 


\section{Appendix A}

Table A1. The complete form of the questionnaire.

\begin{tabular}{|c|c|c|}
\hline Section & Question & Options \\
\hline \multirow{6}{*}{$\begin{array}{l}\text { Demographic } \\
\text { information of } \\
\text { respondent }\end{array}$} & Q1. Gender & $\begin{array}{l}\text { (a) Male } \\
\text { (b) Female }\end{array}$ \\
\hline & Q2. Age & $\begin{array}{l}\text { (a) }<20 \\
\text { (b) } 20 \sim 35 \\
\text { (c) } 35 \sim 50 \\
\text { (d) } 50 \sim 65 \\
\text { (e) }>65\end{array}$ \\
\hline & Q3. Level of education & $\begin{array}{l}\text { (a) High school or below } \\
\text { (b) Technical or bachelor degree } \\
\text { (c) Master degree or above }\end{array}$ \\
\hline & Q4. Monthly income & $\begin{array}{l}\text { (a) }<3,500 \mathrm{RMB} \\
\text { (b) 3,500 10,000 RMB } \\
\text { (c) 10,001 20,000 RMB } \\
\text { (d) }>20,000 \mathrm{RMB}\end{array}$ \\
\hline & Q5. Occupation & $\begin{array}{l}\text { (a) Works as a civil servant } \\
\text { (b) Works in public sector } \\
\text { (c) Self-employed } \\
\text { (d) Works for private firm } \\
\text { (e) Other }\end{array}$ \\
\hline & Q6. Time of residence in Beijing & $\begin{array}{l}\text { (a) }<1 \text { year } \\
\text { (b) } 1 \sim 5 \text { years } \\
\text { (c) } 5 \sim 10 \text { years } \\
\text { (d) }>10 \text { years }\end{array}$ \\
\hline \multirow{3}{*}{$\begin{array}{l}\text { Knowledge about } \\
\text { surveillance cameras }\end{array}$} & Q7. Whether contact video surveillance systems in life? & $\begin{array}{l}\text { (a) Yes } \\
\text { (b) No }\end{array}$ \\
\hline & Q8. Whether handle video surveillance systems in work? & $\begin{array}{l}\text { (a) Yes } \\
\text { (b) No }\end{array}$ \\
\hline & $\begin{array}{l}\text { Q9. Do you have knowledge about the structure and } \\
\text { operation of video surveillance systems? }\end{array}$ & $\begin{array}{l}\text { (a) Yes } \\
\text { (b) No }\end{array}$ \\
\hline \multirow{5}{*}{$\begin{array}{l}\text { Perceptions and attitudes } \\
\text { towards surveillance } \\
\text { cameras }\end{array}$} & Q10. Video surveillance systems can reduce crimes & $\begin{array}{l}\text { (a) Disagree } \\
\text { (b) Partly disagree } \\
\text { (c) Staying neutral } \\
\text { (d) Partly agree } \\
\text { (e) Agree }\end{array}$ \\
\hline & Q11. Video surveillance systems can reduce accidents & $\begin{array}{l}\text { (a) Disagree } \\
\text { (b) Partly disagree } \\
\text { (c) Staying neutral } \\
\text { (d) Partly agree } \\
\text { (e) Agree }\end{array}$ \\
\hline & Q12. Current quantity surveillance cameras are enough & $\begin{array}{l}\text { (a) Disagree } \\
\text { (b) Partly disagree } \\
\text { (c) Staying neutral } \\
\text { (d) Partly agree } \\
\text { (e) Agree }\end{array}$ \\
\hline & Q13. Residence with video surveillance systems are safer & $\begin{array}{l}\text { (a) Disagree } \\
\text { (b) Partly disagree } \\
\text { (c) Staying neutral } \\
\text { (d) Partly agree } \\
\text { (e) Agree }\end{array}$ \\
\hline & $\begin{array}{l}\text { Q14. Choose routes with video surveillance systems would } \\
\text { be more preferable }\end{array}$ & $\begin{array}{l}\text { (a) Disagree } \\
\text { (b) Partly disagree } \\
\text { (c) Staying neutral } \\
\text { (d) Partly agree } \\
\text { (e) Agree }\end{array}$ \\
\hline
\end{tabular}


Table A1. Cont.

\begin{tabular}{|c|c|c|}
\hline Section & Question & Options \\
\hline & $\begin{array}{l}\text { Q15. Video surveillance systems make people behave more } \\
\text { cautious }\end{array}$ & $\begin{array}{l}\text { (a) Disagree } \\
\text { (b) Partly disagree } \\
\text { (c) Staying neutral } \\
\text { (d) Partly agree } \\
\text { (e) Agree }\end{array}$ \\
\hline & Q16. Video surveillance systems bring pressure on people & $\begin{array}{l}\text { (a) Disagree } \\
\text { (b) Partly disagree } \\
\text { (c) Staying neutral } \\
\text { (d) Partly agree } \\
\text { (e) Agree }\end{array}$ \\
\hline & $\begin{array}{l}\text { Q17. Moving surveillance cameras enhance above } \\
\text { perceptions }\end{array}$ & $\begin{array}{l}\text { (a) Disagree } \\
\text { (b) Partly disagree } \\
\text { (c) Staying neutral } \\
\text { (d) Partly agree } \\
\text { (e) Agree }\end{array}$ \\
\hline & $\begin{array}{l}\text { Q18. Less or no video surveillance systems would worsen } \\
\text { public security }\end{array}$ & $\begin{array}{l}\text { (a) Disagree } \\
\text { (b) Partly disagree } \\
\text { (c) Staying neutral } \\
\text { (d) Partly agree } \\
\text { (e) Agree }\end{array}$ \\
\hline
\end{tabular}

\section{References}

1. Hsieh, Y.C.; Lee, Y.C.; You, P.S.; Chen, T.C. An immune based two-phase approach for the multiple-type surveillance camera location problem. Expert Syst. Appl. 2009, 36, 10634-10639. [CrossRef]

2. Wang, X. Intelligent multi-camera video surveillance: A review. Pattern Recogn. Lett. 2013, 34, 3-19. [CrossRef]

3. Li, H.; Graham, D.J. Heterogeneous treatment effects of speed cameras on road safety. Accid. Anal. Prev. 2016, 97, 153-161. [CrossRef] [PubMed]

4. Athanesious, J.J.; Suresh, P. Systematic survey on object tracking methods in video. Int. J. Adv. Res. Comput. Eng. Technol. 2012, 1, 242-247.

5. Tsakanikas, V.; Dagiuklas, T. Video surveillance systems-current status and future trends. Comput. Electr. Eng. 2018, 70, 736-753. [CrossRef]

6. Yang, H.M.; Kriegman, J.D.; Ahuja, N. Detecting faces in images: A survey. IEEE Trans. PAMI 2002, 24, 34-58. [CrossRef]

7. Broeders, D. Breaking Down Anonymity: Digital Surveillance of Irregular Migrants in Germany and the Netherlands; Amsterdam University Press: Amsterdam, The Netherlands, 2009.

8. Zafeiriou, S.; Zhang, C.; Zhang, Z. A survey on face detection in the wild: Past, present and future. Comput. Vis. Image. Understand. 2015, 138, 1-24. [CrossRef]

9. Zhou, Z.; Wang, Y.; Teoh, E.K. A framework for semantic people description in multi-camera surveillance systems. Image Vis. Comput. 2016, 46, 29-46. [CrossRef]

10. Cristani, M.; Raghavendra, R.; Del Bue, A.; Murino, V. Human behavior analysis in video surveillance: A Social Signal Processing perspective. Neurocomputing 2013, 100, 86-97. [CrossRef]

11. Jin, Z.; Bhanu, B. Analysis-by-synthesis: Pedestrian tracking with crowd simulation models in a multi-camera video network. Comput. Vis. Image Understand. 2015, 134, 48-63. [CrossRef]

12. Brown, B. Controlling crime and delinquency in the schools: An exploratory study of student perceptions of school security measures. J. Sch. Violence 2006, 4, 105-125. [CrossRef]

13. Johnson, S.L.; Bottiani, J.; Waasdorp, T.E.; Bradshaw, C.P. Surveillance or safekeeping? How school security officer and camera presence influence students' perceptions of safety, equity, and support. J. Adolesc. Health 2018, 63, 732-738. [CrossRef] [PubMed]

14. Porter, B.; Berry, T. A nationwide survey of self-reported red light running: Measuring prevalence, predictors, and perceived consequences. Acc. Anal. Prev. 2001, 33, 735-741. [CrossRef]

15. Higgins, L.M.; Shaw, W.D.; Egbendewe-Mondzozo, A. Attributes affecting preferences for traffic safety camera programs. Acc. Anal. Prev. 2011, 43, 1042-1048. [CrossRef] [PubMed]

16. Elmaghraby, A.S.; Losavio, M.M. Cyber security challenges in smart cities: Safety, security and privacy. J. Adv. Res. 2014, 5, 491-497. [CrossRef] [PubMed] 
17. Van Zoonen, L. Privacy concerns in smart cities. Gov. Inf. Q. 2016, 33, 472-480. [CrossRef]

18. Braun, T.; Fung, B.C.M.; Iqbal, F.; Shah, B. Security and privacy challenges in smart cities. Sustain. Cities Soc. 2018, 39, 499-507. [CrossRef]

19. Fistola, R.; Gargiulo, C.; Battarra, R.; La Rocca, R.A. Sustainability of urban functions: Dealing with tourism activity. Sustainability 2019, 11, 1071. [CrossRef]

20. Martínez-Béjar, R.; Brändle, G. Contemporary technology management practices for facilitating social regulation and surveillance. Technol. Soc. 2018, 54, 139-148. [CrossRef]

21. Steinfeld, N. Track me, track me not: Support and consent to state and private sector surveillance. Telemat. Inf. 2017, 34, 1663-1672. [CrossRef]

22. Peña-García, A.; Hurtado, A.; Aguilar-Luzón, M.C. Impact of public lighting on pedestrians' perception of safety and well-being. Saf. Sci. 2015, 78, 142-148. [CrossRef]

23. Zhang, B. Absolutely Everywhere in Beijing Is Now Covered by Police Video Surveillance, 2015. Available online: https:/ / qz.com/518874/absolutely-everywhere-in-beijing-is-now-covered-by-policevideo-surveillance/ (accessed on 30 October 2018).

24. National Bureau of Statistics of China, 2018. Available online: http://data.stats.gov.cn/ (accessed on 30 October 2018).

25. Walden, T.D. Analysis of the Effectiveness of Photographic Traffic Signal Enforcement Systems in Texas; Report Prepared for the Traffic Operations Division; Texas Department of Transportation: Austin, TX, USA, 2008.

26. Hernandez, R. Traffic-camera debate heats up campaign trails. New York Times, 7 August 2011.

27. Retting, R.A.; Williams, A.F.; Farmer, C.M.; Feldman, A. Evaluation of red light camera enforcement in Oxnard, California. Acc. Anal. Prev. 1999, 31, 169-174. [CrossRef]

28. Wong, S.C.; Wong, C.W.; Sze, N.N. Attitudes of public light bus drivers to penalties to combat red light violations in Hong Kong. Transp. Policy 2008, 15, 43-54. [CrossRef]

29. Van Bommel, M.; van Prooijen, J.; Elffers, H.; van Lange, P.A. Be aware to care: Public self-awareness leads to a reversal of the bystander effect. J. Exp. Soc. Psychol. 2012, 48, 926-930. [CrossRef]

30. Darley, J.M.; Latané, B. Bystander intervention in emergencies: Diffusion of responsibility. J. Person. Soc. Psychol. 1968, 8, 377-383. [CrossRef]

31. Flach, J.M. Situation awareness: Proceed with caution. Hum. Fact. J. Hum. Fact. Ergon. Soc. 1995, 37, $149-157$. [CrossRef]

32. Hoyle, R.H. Personality and self-regulation. In Handbook of Personality and Self-Regulation; Wiley-Blackwell: Hoboken, NJ, USA, 2010.

33. Sun, M.; Yang, X.; Huisingh, D.; Wang, R.; Wang, Y. Consumer behaviour and perspectives concerning spent household battery collection and recycling in China: A case study. J. Clean. Prod. 2015, 107, 775-785. [CrossRef]

34. Gu, F.; Guo, J.; Yao, X.; Summers, P.A.; Widijatmoko, S.D.; Hall, P. An investigation of the current status of recycling spent lithium-ion batteries from consumer electronics in China. J. Clean. Prod. 2017, 161, 765-780. [CrossRef]

35. Langer, K.; Decker, T.; Roosen, J.; Menrad, K. Factors influencing citizens' acceptance and non-acceptance of wind energy in Germany. J. Clean. Prod. 2018, 175, 133-144. [CrossRef]

36. Jörissen, J.; Priefer, C.; Bräutigam, K.-R. Food waste generation at household level: Results of a survey among employees of two European research centers in Italy and Germany. Sustainability 2015, 7, 2695-2715. [CrossRef]

37. Wang, S.; Wang, J.; Lin, S.; Li, J. Public perceptions and acceptance of nuclear energy in China: The role of public knowledge, perceived benefit, perceived risk and public engagement. Energ. Policy 2019, 126, 352-360. [CrossRef]

38. Zaunbrecher, B.S.; Bexten, T.; Wirsum, M.; Ziefle, M. What is stored, why, and how? Mental models, knowledge, and public acceptance of hydrogen storage. Energ. Proc. 2016, 99, 108-119. [CrossRef]

39. Prue, G.; Shapiro, G.; Maybin, R.; Santin, O.; Lawler, M. Knowledge and acceptance of human papillomavirus (HPV) and HPV vaccination in adolescent boys worldwide: A systematic review. J. Cancer Policy 2016, 10, 1-15. [CrossRef]

40. Russell, C.J.; Bobko, P. Moderated regression analysis and Likert scales: Too coarse for comfort. J. Appl. Psychol. 1992, 77, 336-342. [CrossRef] [PubMed]

41. Li, Q. A novel Likert scale based on fuzzy sets theory. Expert Syst. Appl. 2013, 40, 1609-1618. [CrossRef] 
42. Zhang, X.C.; Kuchinke, L.; Woud, M.L.; Velten, J.; Margarf, J. Survey method matters: Online/offline questionnaires and face-to-face or telephone interviews differ. Comput. Hum. Behav. 2017, 71, 172-180. [CrossRef]

43. Booth-Kewley, S.; Edwards, J.E.; Rosenfeld, P. Impression management, social desirability, and computer administration of attitude questionnaires: Does the computer make a difference? J. Appl. Psychol. 1992, 77, 562-566. [CrossRef]

44. Knapp, H.; Kirk, S.A. Using pencil and paper, Internet and touch-tone phones for self-administered surveys: Does methodology matter? Comput. Hum. Behav. 2003, 19, 117-134. [CrossRef]

45. Statista. Most Popular Mobile Messaging Apps Worldwide as of April 2018, Based on Number of Monthly Active Users (in Millions), 2018. Available online: https://www.statista.com/statistics/258749/mostpopular-global-mobile-messenger-apps / (accessed on 30 October 2018).

46. Kong, Y.; Seo, Y.S.; Zhai, L. Comparison of reading performance on screen and on paper: A meta-analysis. Comput. Educ. 2018, 123, 138-149. [CrossRef]

47. Gu, F.; Hall, P.; Miles, M.J. Performance evaluation for composites based on recycled polypropylene using principal component analysis and cluster analysis. J. Clean. Prod. 2016, 115, 343-353. [CrossRef]

48. Gu, F.; Hall, P.; Miles, M.J. Development of composites based on recycled polypropylene for injection moulding automobile parts using hierarchical clustering analysis and principal component estimate. J. Clean. Prod. 2016, 137, 632-643. [CrossRef]

49. Joliffe, I.T. Principal Component Analysis, 2nd ed.; Springer: New York, NY, USA, 2002.

50. Cerny, C.A.; Kaiser, H.F. A study of a measure of sampling adequacy for factor-analytic correlation matrices. Multivar. Behav. Res. 1977, 12, 43-47. [CrossRef] [PubMed]

51. Bartlett, M.S. Properties of sufficiency and statistical tests. Proc. R. Stat. Soc. Ser. A 1937, 160, $268-282$. [CrossRef]

52. Rodgers, J.L.; Nicewander, W.A. Thirteen ways to look at the correlation coefficient. Am. Stat. 1988, 42, 59-66. [CrossRef]

53. Yao, Y. Does higher education expansion enhance productivity? J. Macroecon. 2019, 59, 169-194. [CrossRef]

54. Choy, L.H.T.; Li, V.J. The role of higher education in China's inclusive urbanization. Cities 2017, 60, 504-510. [CrossRef]

(C) 2019 by the authors. Licensee MDPI, Basel, Switzerland. This article is an open access article distributed under the terms and conditions of the Creative Commons Attribution (CC BY) license (http://creativecommons.org/licenses/by/4.0/). 